\title{
PSICOLINGUÍSTICA DO BILINGUISMO: IMPLICAÇÕES EM PROCESSOS FORMAIS DE AQUISIÇÃO DE LÍNGUAS
}

\author{
Elena Ortiz-Preuss ${ }^{*}$ \\ ${ }^{1}$ Universidade Federal de Goiás, Goiânia, GO, Brasil
}

\begin{abstract}
Resumo
Neste artigo ${ }^{1}$ discutimos asinter-relações entre variáveis contextuais e individuais na aquisição e uso de segunda língua (L2), a partir de pesquisas desenvolvidas emnosso grupo de estudo. Partimos do pressuposto de que, na aquisição tardia de L2, há variabilidade na proficiência dos aprendizes, sendo necessário (re)conhecer os efeitos das variáveis individuais nos processos de ensino-aprendizagem. Os experimentos, criados à luz da psicolinguística do bilinguismo e realizados em contextos formais de aquisição, avaliaram associações entre sistemas de atenção e de memória de trabalho (MT) e o desempenho de bilíngues na L2. Os resultados, ainda que incipientes, indicam que efeitos de abordagens pedagógicas podem ser afetados por diferenças individuais. Ademais, revelam a necessidade de mais experimentosque enfoquem essas variáveis nos processos de ensino-aprendizagem de L2.

Palavras-chave: Condições Pedagógicas; Diferenças Individuais; Psicolinguística; Bilinguismo.
\end{abstract}

\section{PSYCHOLINGUISTICS OF BILINGUALISM: IMPLICATIONS IN FORMAL PROCESSES OF LANGUAGE ACQUISITION}

\begin{abstract}
In this article we discuss the interrelationships between contextual and individual variables in the acquisition and use of $\mathrm{L} 2$, based on researches developed by our team. We assume that in the late acquisition of L2 there is variability in the proficiency of the learners, and that it is necessary to (re)know the effects of the individual variables in the teachinglearning processes. The experiments, which were created according to the Psycholinguistics of bilingualism and carried out in formal contexts of acquisition, evaluated associations between attention and working memory systems and the performance of bilinguals in their L2. The results, although incipient, indicate that effects of pedagogical approaches can be affected by individual differences. In addition, they reveal the need of more experiments that focus these variables on L2 teaching-learning processes.

Keywords: Pedagogical Conditions; Individual Differences; Psycholinguistics; Bilingualism.
\end{abstract}

\footnotetext{
* Docente do Programa de Pós-graduação em Letras e Linguística da Universidade Federal de Goiás (UFG). Doutora em Estudos da Linguagem, pela Universidade Federal do Rio Grande do Sul (UFRGS). Fez estágio pósdoutoral na Georgetown University, com bolsa CAPES. E-mail: elena@ufg.br. ORCID: 0000-0002-8149-7738.
} 


\section{Introdução}

A área de Aquisição de Segunda Língua (ASL) tem buscado compreender e explicar como ocorre a aquisição de línguas, de modo a poder indicar o melhor método ou enfoque de ensino. Muitos estudos nessa área visam observar as vantagens de abordagens implícitas e explícitas, tendo como referência concepções teóricas "generalizantes", ou seja, que pretendem oferecer uma explicação abrangente do processo, apontando um padrão de aprendizagem comum a todos os aprendizes, como, por exemplo, o behaviorismo e ointeracionismo, entre outros (ORTIZ-PREUSS; SANZ, 2016; SANZ; SERAFINI, 2018).

Porém, indivíduos que adquiriram a L2 tardiamente têm alcançado níveis diferentes de proficiência nessa língua, embora tenham frequentado os mesmos contextos de ensino-aprendizagem. Essa variabilidade nos níveis de proficiência põe em xeque o poder explicativo de muitas teorias de aquisição e, muitas vezes, tem sido justificada pelas diferenças individuais $\left(\mathrm{DIs}^{2}\right)$ dos aprendizes, ainda que sem muito detalhamento sobre como as DIs afetam a intervenção pedagógica. Isso mostra, portanto, que a abordagem em si não é suficiente para garantir o resultado final esperado e que variáveis individuais podem ter alto impacto no processo de aquisição de línguas (SANZ, 2005).

Em particular, temos nos dedicado a pesquisar como ocorre a aquisição de L2, especificamente o espanhol por falantes de português, e constatamos que o resultado da aquisição depende de interações entre variáveis individuais e contextuais, as quais serão expostas neste artigo. Nossos estudos, de natureza semi-experimental (REZNITSKAYA, 2008), enquadram-se na área denominada psicolinguística do bilinguismo e objetivam verificar a eficácia de diferentes tipos de intervenção pedagógica, correlacionando os dados com características pessoais dos participantes, a saber, conhecimento linguístico prévio, inibição, capacidade de memória de trabalho e atenção, ${ }^{3}$ que serão detalhados na próxima seção.

O propósito deste artigo é expor um panorama de recentes pesquisas desenvolvidas em nosso grupo de estudos nessa perspectiva interativa e refletir sobre o potencial impacto desses resultados para os contextos de ensino e aprendizagem de línguas.Para isso, na próxima seção apresentaremos um breve panorama sobre a aquisição de L2, descrevendo as variáveis individuais e contextuais ${ }^{4}$ que interferem no processo. Posteriormente, discutiremos alguns estudos sobre aquisição de línguas no escopo da psicolinguística do bilinguismo e em seguida apresentaremos sinteticamente pesquisas que visavam observar a interação entre condições pedagógicas e variáveis individuais na aquisição de línguas. Finalmente, apresentamos algumas considerações, seguidas das referências. 


\section{Referencial Teórico}

\subsection{Aquisição de L2: breve panorama}

Conforme mencionado anteriormente, compreender e explicar como ocorre a aquisição e uso de L2 tem sido o foco de muitas pesquisas na ASL. É interessante mencionar que no histórico do ensino de línguas houve um movimento pendular que influenciou significativamente as abordagens de ensino, ao longo dos anos. Inicialmente, a aquisição $0^{5}$ de L2, inspirada na aprendizagem de línguas clássicas, como grego e latim, era entendida como o resultado do estudo gramatical e da tradução de textos. Posteriormente, sob forte influência do behaviorismo, o ensino de línguas se centrou na abordagem explícita de regras e repetição estrutural, o que veio a ser denominado como "foco nas formas", por não haver a preocupação de oferecer ensino contextualizado, incluindo comunicação efetiva (LONG; ROBINSON, 1998).

Entretanto, tais abordagens não conseguiam alcançar aquilo que mais tarde veio a ser conhecido como competência comunicativa, cujo foco era o conhecimento linguístico necessário para uma comunicação eficaz. Daí surgiu uma mudança significativa de enfoque, conhecida como ensino com "foco no significado", baseado no modo como as crianças adquirem a sua primeira língua (L1). Essa nova perspectiva considerava supérflua qualquer abordagem estrutural e enfatizava que o ensino devia se pautar em situações comunicativas nas quais o aprendiz era imerso. Em outras palavras, a aquisição ocorreria como consequência da exposição à L2. Entretanto, essa nova abordagem também não se mostrou plenamente suficiente, dentre outras razões, porque somente a evidência positiva, ou seja, a exposição à L2, não pareceu ser suficiente para a aquisição de certos contrastes gramaticais entre a L1 e a L2 e isso afetava o domínio da L2 (LONG; ROBINSON, 1998).

Diante dessa realidade, um novo movimento pendular ocorreu em direção a uma posição intermediária, denominada de "foco na forma", a qual recuperava o papel importante da reflexão gramatical para o desenvolvimento linguístico na L2, desde que ocorresse de forma contextualizada e para atender a um propósito comunicativo. Ressalta-se que o foco na forma pode ocorrer de modo reativo, isto é, a partir de uma necessidade evidenciada pelo aprendiz (na forma de pergunta ou resposta a uma atividade, por exemplo), ou proativo, quando o professor antecipa possíveis dificuldades linguísticas dos aprendizes para realizar determinada tarefa e promove uma intervenção prévia (LONG; ROBINSON, 1998; ELLIS, 1998, 2005).

É necessário mencionar que, ao longo dos anos, foram encontradas evidências de efeitos tanto de abordagens mais implícitas quanto de abordagens mais explícitas na aquisição de L2 (BOWDEN, SANZ, STAFFORD, 2005; DOUGHTY; WILLIAMS, 2009; GASS; SELINKER, 2008; SANZ, 2005).A diferença fundamental entre abordagens mais implícitas ou mais explícitas de ensino está relacionada com o nível de consciência envolvido nas intervenções 
pedagógicas. Entretanto, a consciência é um construto de ordem cognitiva individual e que guarda estreita relação com outros sistemas cognitivos relacionados, como, atenção, memória e controle executivo. Schmidt (1990, 1994 e 1995) discute a relação entre consciência e aprendizagem consciente. O autor (op.cit.) argumenta que a consciência é um sistema cognitivo que abrange intenção, controle, ciência e atenção, e que estes dois últimos componentes estão diretamente relacionados com a aprendizagem. Ainda, de acordo com Schmidt (2001), em sua hipótese do noticing, a consciência como ciência pode ocorrer em nível de percepção (mais superficial) e de compreensão (mais profundo), mas para que a aquisição de L2 aconteça, os aprendizes devem registrar conscientemente a estrutura, ou seja, prestar atenção e notar a forma-alvo ao compreender o input. Em outras palavras, o noticing ocorre numa etapa intermediária entre os níveis de percepção e de compreensão da consciência como ciência e contribui para a aquisição de L2.

As pesquisas em ASL, por sua vez, preocuparam-se em investigar como determinadas intervenções pedagógicas afetavam o processo de aquisição. Sob essa perspectiva, avaliavama eficácia de cada abordagem de ensino da L2, em cada uma das principais etapas do processo (1-Input $>2$-Intake $>3$-Interlíngua $>4$-Output). Cabe mencionar que o input se refere a toda amostra ou insumo linguístico na $\mathrm{L} 2$ recebido pelo aprendiz (seja oral, seja escrito). O intake se refere à porção do input que é processada pelo aprendiz e mantida na sua memória de trabalho durante a tarefa de compreensão em tempo real (online) (VANPATTEN, 2005). O sistema de interlíngua se constitui das representações mentais da L2, oriunda de dados do intake que foram armazenados na memória de longo prazo. O output, por sua vez, se refere ao uso do conhecimento nas tarefas de produção orais e/ou escritas (ELLIS, 1998; GASS e SELINKER, 2008; IZUMI, 2013)

É importante mencionar que houve mudanças no modo como o processo de aquisição de línguas era concebido. Inicialmente, por influência da teoria de processamento da informação, esse processo era concebido como linear, passando pelas 4 etapas sequenciais supracitadas, isto é, iniciando com o input e encerrando no output. Entretanto, atualmente o processo é considerado cíclico, ou seja, não se encerra no output, pois este pode se tornar um novo input e, assim, dar início a um novo ciclo (ELLIS, 1998; GASS e SELINKER, 2008; IZUMI, 2013), conforme ilustra a Figura 1: 
Figura 1: Processo de aquisição de línguas

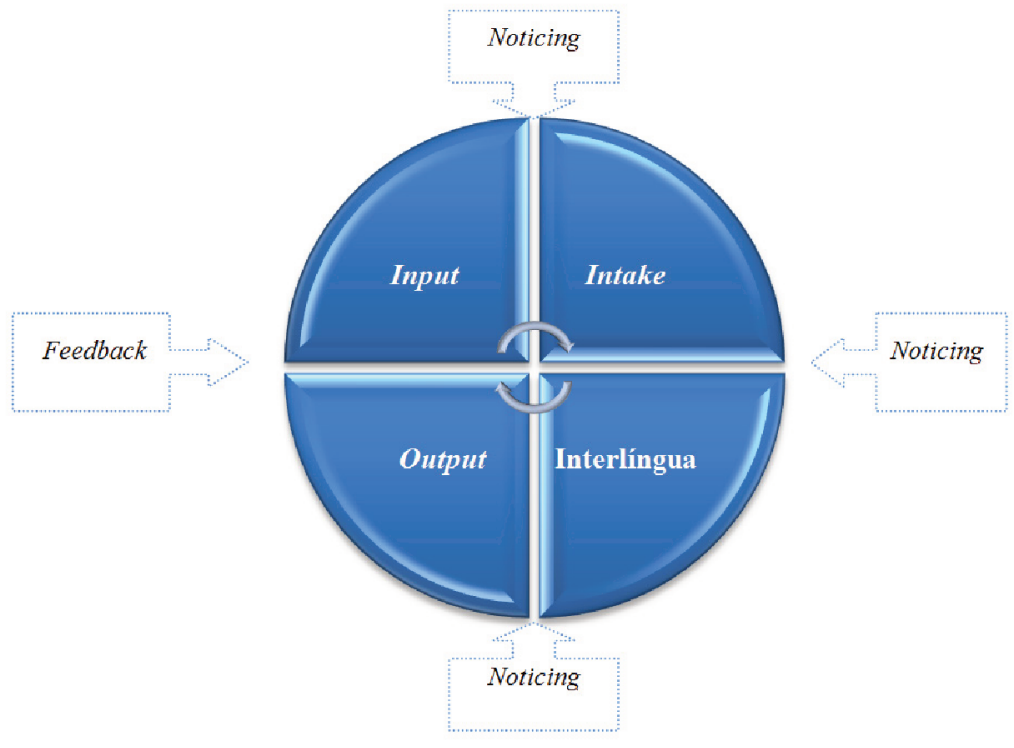

Nota: Elaboração própria, a partir de GASS e SELINKER (2008, p. 373) e IZUMI (2013, p. 29)

Conforme a imagem, numa concepção cíclica, as quatro etapas básicas, inseridas no círculo, retroalimentam-se, de modo que o output pode ser o gatilho de um novo ciclo, servindo como um novo input. Além disso, há outros dois processos que podem afetar essas fases: o noticing, que corresponde ao registro consciente (resultado da ação de prestar atenção e notar conscientemente a forma) de determinada estrutura pelo aprendiz, conforme discutido anteriormente, e o feedback, que corresponde à avaliação da produção do aprendiz. De acordo com Izumi (2013), o noticing pode ocorrer nos seguintes intervalos: 1) entre input e intake (registro consciente da relação forma-significado-função da estrutura linguística - noticing form); 2) entre intake e interlíngua (registro consciente da lacuna entre o conhecimento na interlíngua e a forma-alvo - noticing gap between interlanguage and target language); e 3 ) entre interlíngua e output (registro consciente da diferença na habilidade de uso - noticing hole /gap in ability). Por sua vez, o feedback ocorre somente a partir da produção do aprendiz, através de correção explícita ou implícita, por exemplo (ELLIS, 1998; 2005).

Sanz (2005) argumenta que os tipos de intervenção pedagógica (modo de exposição ao input, tipo de prática e de feedback fornecido) compõem o conjunto de variáveis externas ou contextuais de aquisição de línguas, as quais envolvem também o contexto de aquisição (natural ou formal), bem como a quantidade e qualidade do input e da interação. Cabe salientar que as pesquisas têm observado efeitos de diferentes tipos de intervençôes pedagógicas específicas a cada uma das etapas do processo de aquisição, conforme ilustra a Figura 2 (BOWDEN, SANZ, STAFFORD, 2005; DOUGHTY; WILLIAMS, 2009; GASS; SELINKER, 2008; SANZ, 2005). 
Figura 2: Intervenções pedagógicas no processo de aquisição de L2

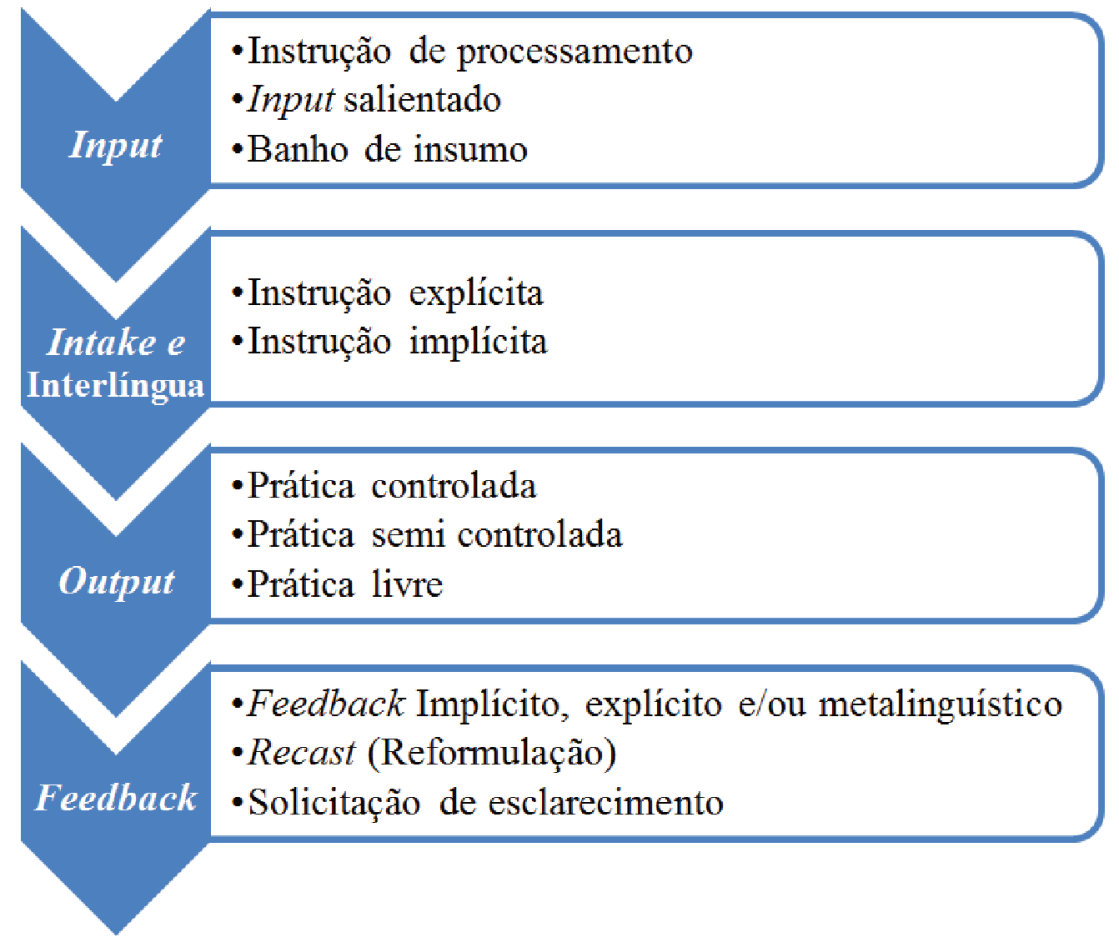

Nota: Elaboração própria

A Figura 2 ilustra que cada intervenção ${ }^{6}$ pode enfocar uma etapa diferente do processo de aquisição. A instrução de processamento ${ }^{7}$, por exemplo, proposta por VanPatten $(1996,2002,2005)$, enfoca processos psicolinguísticos relacionados com a compreensão do input na L2 e visa auxiliar as conexões entre forma e significado, bem como facilitar o intake. Por sua vez, os tipos de instrução formalatuam na etapa de intake e interlíngua, pois estão relacionados à retenção do conhecimento, seja por meio de inferência sobre o uso de determinada estrutura (implícita), seja através da focalização da atenção do aprendiz na estrutura-alvo (explícita). $\mathrm{Na}$ etapa de output, os tipos de prática desempenham papel central, pois atuam na apropriação e uso do conhecimento linguístico nas produções orais e/ou escritas, podendo seguir um fluxo de práticas mais controladas até as práticas livres. Finalmente, após a produção, o feedback recebido, o qual pode ser fornecido de modo explícito (correção explícita, feedback metalinguístico) ou implícito (reformulações, repetição, etc.), pode contribuir para a consolidação do conhecimento e da habilidade de uso linguístico (ELLIS, 1998; 2005).

Cabe ressaltar que, como já foi mencionado, os efeitos de cada intervenção podem ser afetados por características individuais dos aprendizes. Bowden, Sanz e Stafford (2005) argumentam que memória e consciência, assim como idade, personalidade, estilo cognitivo, especialização cerebral, conhecimento prévio, entre outros, formam o conjunto de variáveis ou diferenças individuais (DIs). Nesse sentido, é necessário analisar efeitos de diferentes tipos de intervenções, como as que compóem a Figura 2, correlacionados com resultados de testes cog- 
nitivos de atenção e memória. Em outras palavras, é preciso analisar o desenvolvimento linguístico pelo viés da psicolinguística do bilinguismo.

\subsection{Psicolinguística do bilinguismo e aquisição de L2}

Para situar o escopo da psicolinguística do bilinguismo, primeiramente, vamos delinear o foco e abrangência da Psicolinguística. Conforme Leitão (2015), a Psicolinguística investiga como as pessoas adquirem, compreendem e produzem a linguagem, sendo que a psicolinguística desenvolvimentista investiga a aquisição da linguagem, ao passo que a psicolinguística experimental estuda a compreensão e a produção linguística. Note-se que tanto a psicolinguística desenvolvimentista quanto a psicolinguística experimental abrangem pesquisas envolvendo um sistema linguístico. Por sua vez, a psicolinguística do bilinguismo, conforme Finger e Ortiz-Preuss (2018), investiga a aquisição, compreensão e produção de duas ou mais línguas, ou seja, como ocorre o processamento linguístico e cognitivo, quando mais de um sistema linguístico está envolvido, e quais mecanismos e procedimentos são necessários para potencializar a aquisição e uso das línguas.

Considerando o exposto, partimos do pressuposto de que a aprendizagem de L2 se baseia numa série de processos cognitivos e de que analisar o processo de aquisição de L2, a partir do escopo da psicolinguística do bilinguismo, permite verificar como as diferenças individuais nos sistemas cognitivos dos participantes podem interferir nos efeitos das intervenções pedagógicas.

Novamente, salientamos que há evidências de que os efeitos de instrução dependem de características individuais dos aprendizes, tais como a idade e a capacidade de memória de trabalho. Idosos, por exemplo, parecem se beneficiar mais de instrução implícita doque jovens, os quais obtêm mais vantagem com a instrução explícita. Por sua vez, intervenções com instrução implícita demandam mais do sistema de memória de trabalho, ao passo que a instrução explícita, combinada com prática e feedback, minimizam o impacto da memória de trabalho (ORTIZ-PREUSS; SANZ, 2016; SANZ; SERAFINI, 2018).

A aquisição de L2 envolve vários sistemas cognitivos, dentre os quais apresentaremos com mais detalhe, além da memória de trabalho, o controle executivo e o sistema atencional, por terem sido foco de nossos estudos. Conforme mencionado anteriormente, a memória de trabalho mantém relação com os demais sistemas cognitivos e com a aprendizagem. Trata-se de um sistema de retenção temporária e de processamento de informação necessária para a execução de uma tarefa, sendo considerada, portanto, uma memória operacional (JUFFS; HARRINGTON, 2011). A memória de trabalho atua em todas as tarefas linguísticas, pois é um sistema que gerencia o processo de ativação de palavras, de recuperação de propriedades sintáticas para o ordenamento de sentenças e de conexão de informações recebidas com informações ativadas na memória de longo prazo. Pesquisadores de L2 buscam compreender como a capacidade de memória de trabalho pode explicar a variabilidade na aprendizagem e uso dessa língua. Para estabelecer a conexão entre as informações do contexto da tarefa e 
as informações que precisam ser recuperadas na memória de longo prazo, a memória de trabalho aciona 3 diferentes subcomponentes especializados: o esboço visuo-espacial, que trata de informações visuais e espaciais; a alça fonológica, que trata de informações fonológicas; e o buffer episódico, que estabelece interface entre os sistemas de memória e as informações visuais, espaciais e fonológicas Esses 3 subcomponentes são subordinados a um sistema principal, denominado executivo central, que gerencia e coordenada todos os processos de ativação, retenção e processamento de informações na memória de trabalho (BADDELEY, 2011; BADDELEY, 2002).

Há vários testes para medir a capacidade da memória de trabalho, ou seja, a quantidade máxima de itens ativados e disponíveis (palavra, frase, número, etc.) para o armazenamento e processamento nessa memória (JUST; CARPENTER, 1992). Por exemplo, a tarefa Alpha Span mede a quantidade de palavras repetidas em ordem alfabética, após a leitura de listas de palavras isoladas, e a tarefa Reading Span mede a quantidade de palavras recordadas, ao executar simultaneamente uma tarefa de ler frases, responder se elas têm sentido e memorizar a última palavra de cada frase (KRAMER, 2011; RIGATTI, 2015). Note-se que a segunda tarefa é mais complexa do que a primeira, pois além da retenção requer o processamento de informações.

Além desse sistema operacional, no processamento da linguagem e na comunicação, mecanismos de controle executivo são fundamentais. O controle executivo conta com pelo menos 2 componentes: o monitoramento, que avalia situações de conflito e desencadeia ajustes de processamento; e a resolução de conflito, que organiza comportamentos, conforme objetivos, seja realçando informações relevantes, seja suprimindo informações irrelevantes na execução de determinada tarefa. No caso do bilinguismo, destaca-se o processo de inibição que visa suprimir uma representação ativa ou tendência de ação para controlar qual língua usar ou alternar entre uma e outra língua. (YE; ZHOU, 2009). Esse mecanismo é crucial na produção de fala, pois o bilíngue precisa inibir o sistema linguístico não-alvo da comunicação e selecionar palavras ativadas na língua-alvo, evitando interferências entre as línguas. Ressaltamos que para haver inibição os demais componentes (monitoramento e resolução de conflito) devem ter exercido suas funções adequadamente.

Uma das formas de avaliar a funcionalidade do controle executivo é por meio do teste Simon, de quadrado ou de flechas. No caso da tarefa Simon de quadrados, o participante deve dizer qual quadrado aparece na tela do computador, pressionando a letra $\mathrm{A}$ se for o azul e a letras L se for o rosa. Na condição congruente, o quadrado aparece no mesmo lado da tecla de resposta (Tecla A e quadrado azul à esquerda e Tecla L e quadrado rosa à direita); na condição incongruente,o quadrado aparece no lado oposto ao da tecla de resposta (quadrado azul à direita e quadrado rosa à esquerda). Na tarefa Simon de flechas, o participante deve indicar para que direçãoestá apontando uma flecha que aparece no lado direito ou no lado esquerdo da tela. Para isso, deverá pressionar a tecla A se a flecha aponta para a esquerda e pressionar a tecla L e se for para a 
direita. Na condição congruente, existe correspondência entre o lado em que a flecha aparece na tela e a direção para a qual está apontando, ao passo que na condição incongruente a flecha aparece no lado oposto ao que está apontando.O comportamento dos participantes é avaliado pelas medidas de acurácia (ACC) e de tempo de resposta (TR).

A tarefa de nomeação de desenhos, envolvendo troca de sistemas linguísticos, é um tipo de tarefa linguística que permite avaliar o controle executivo, uma vez que prevê respostas a condições congruentes (blocos de nomeação na mesma língua) e incongruentes (blocos em que é necessário trocar de sistema linguístico para realizar a nomeação). A língua de nomeação é indicada por uma pista (cor do desenho, por exemplo). Nesse caso, para executar adequadamente a nomeação, é fundamental a atuação dos mecanismos de controle, principalmente, a inibição para suprimir a ativação da língua não-alvo.

Os mecanismos de controle executivo dependem e integram a rede de controle atencional, a qual, segundo Costa, Hernández e Sebastián-Galles (2008), é composta por 3 componentes: alerta, que ativa o estado de alerta; orientação, que seleciona informação sensorial; e controle executivo, que monitora e resolve conflitos. É importante ressaltar que a atenção é um sistema seletivo, de capacidade limitada, que controla o acesso à consciência, estando diretamente relacionada com a aprendizagem, inclusive de línguas (ORTEGA, 2008). Em vista disso, Costa, Santesteban e Ivanova (2006) levantaram a hipótese de que a similaridade linguística pode afetar o funcionamento do sistema atencional, provocando interferências entre as línguas. Os pesquisadores argumentaram que o acesso lexical bilíngüe pode gerar conflito, devido à ativação de palavras, na L1 e na L2, ligadas ao mesmo conceito. Segundo essa hipótese, quanto mais similares forem as línguas/palavras ativadas, mais difícil para o sistema resolver o conflito, logo, maior é a demanda de atenção para garantir que a palavra-alvo na língua-alvo seja selecionada e produzida (ORTIZ-PREUSS, 2014).

O sistema atencional pode ser avaliado pela tarefa de rede de atenção (Attentional Network task - ANT) (COSTA, HERNÁNDEZ e SEBASTIÁN-GALLES, 2008), na qual o participante deve indicar para que lado a flecha central está apontando. Nessa tarefa há 3 condições que possibilitam avaliar o controle executivo: congruente, quando a flecha está ladeada por outras flechas apontando para o mesmo lado; incongruente, quando a flecha está ladeada por outras flechas apontando para o lado oposto; e neutra quando a flecha não está ladeada por outras flechas. Os componentes de alerta e de orientação podem ser avaliados, respectivamente, pelo aparecimento ou não de pistas e a localização do estímulo-alvo. O comportamento dos participantes é avaliado pelas medidas de acurácia (ACC) e de tempo de resposta (TR). Cabe destacar que, pelo seu design, o Teste de ANT também permite avaliar o mecanismo controle executivo, inclusive, Costa, Hernández e Sebastián-Galles (2008) ressalvam que esse teste não sofre interferência de outros sistemas cognitivos. Os pesquisadores (op.cit.) argumentam que no teste Simon de quadrados, como há a necessidade de lembrar diferentes regras de ação conforme a cor, a atuação da memória de trabalho 
é fundamental, portanto, afeta o resultado. No teste ANT isso não ocorre, porque só há uma única regra ao longo de todo o teste.

Nesta seção discutimos brevemente alguns sistemas cognitivos, os quais são foco de nossos estudos sobre o desenvolvimento linguístico de bilíngues português-espanhol. Os experimentos que passaremos a expor na próxima seção tratam da análise da aprendizagem gramatical e da produção de fala, levando em consideração também a similaridade linguística, que pode gerar maior demanda cognitiva para esses bilíngues.

\section{Interação entre variáveis individuais e contextuais na aquisição de L2}

Nosso projeto de pesquisa, intitulado "Condições pedagógicas e variáveis individuais na aquisição de línguas", visa verificar a interação entre variáveis individuais e condições pedagógicas no processo de aquisição de línguas, bem como possui os seguintes objetivos específicos:

1. Traçar um panorama das pesquisas que tratam do processo aquisição de línguas, levando-se em consideração tipo de instrução e variáveis individuais.

2. Discutir a natureza dos conhecimentos implícito e explícito e suas possíveis inter-relações.

3. Observar os efeitos da similaridade linguística na aquisição de línguas.

4. Investigar o papel de mecanismos de memória e atenção no processo de aquisição de línguas.

5. Identificar vantagens e/ou desvantagens de diferentes tipos de instrução.

Para alcançar tais objetivos realizamos experimentos com o foco no ensino de gramática e na produção de fala. Em geral, os estudos ${ }^{8}$ observaram efeitos da similaridade linguística, capacidade de memória de trabalho e/ou de atenção no desenvolvimento linguístico da L2, e, para melhor definir o perfil dos participantes, foi aplicado o Questionário de Experiência Linguística e Proficiência - QELP (MARIAN; BLUMENFELD; KAUSHANSKAYA, 2007; SCHOLL; FONTES, 2015).

Os dois experimentos sobre instrução gramatical foram realizados, utilizando um ambiente virtual de aprendizagem (Moodle) e como instrumentos foram usados pré- e pós-testes linguísticos (envolvendo compreensão e produção de frases, e julgamento de gramaticalidade) e testes cognitivos de atenção e de memória de trabalho.

O primeiro estudo (ORTIZ-PREUSS, 2017) se refere a um experimento que visava verificar efeitos da instrução de processamento sobre o verbo gostar em espanhol, considerando-se o papel da atenção e da similaridade entre as línguas. Essa modalidade de instrução foi testada, tendo em vista que a estrutura do verbo gostar envolve um processamento sintático-semântico diferente no português e 
no espanhol, o que se configura como condição essencial para o uso da instrução de processamento (VANPATTEN, 2005). O experimento foi realizado com uma amostra de conveniência composta por 19 aprendizes brasileiros de espanhol de nível inicial, divididos em dois grupos. O grupo experimental (que receberia somente a instrução de processamento) contava com 8 participantes (24 anos de idade média) e o grupo de controle (que receberia somente a instrução explícita) contava com 11 participantes (27,5 anos de idade média). Os participantes preencheram o QELP e realizaram os testes linguísticos intercalados pelo período de instrução. Os resultados mostraram que não houve efeito significativo da instrução de processamento, devido à inexistência de diferença significativa entre as médias do grupo experimental e do grupo controle, nas diferentes tarefas de compreensão e produção linguística. Diante disso, optou-se por oferecer ao grupo experimental a instrução explícita e se constatou que a instrução de processamento combinada com a instrução explícita contribuiu significativamente para a maior acurácia, principalmente, da produção de frases com a estrutura-alvo. Cabe salientar que a instrução de processamento enfoca, exclusivamente, a exposição e compreensão do input e não requer produção com a estrutura-alvo. Em vista disso, o aumento da produção, após a combinação com instrução explícita, indica que a instrução de processamento pode potencializar o efeito da instrução explícita, sendo, portanto, mais vantajosa ao aprendiz a combinação entre esses dois tipos de instrução.O Gráfico 1 ilustra os resultados dos efeitos somente da instrução de processamento (Pós-teste 1) e da combinação com a instrução explícita (Pós-teste 2), em tarefas de julgamento de gramaticalidade, de identificação do sujeito de frases e de produção de frases.

Gráfico 1: Resultados dos efeitos da instrução de processamento em diferentes tarefas

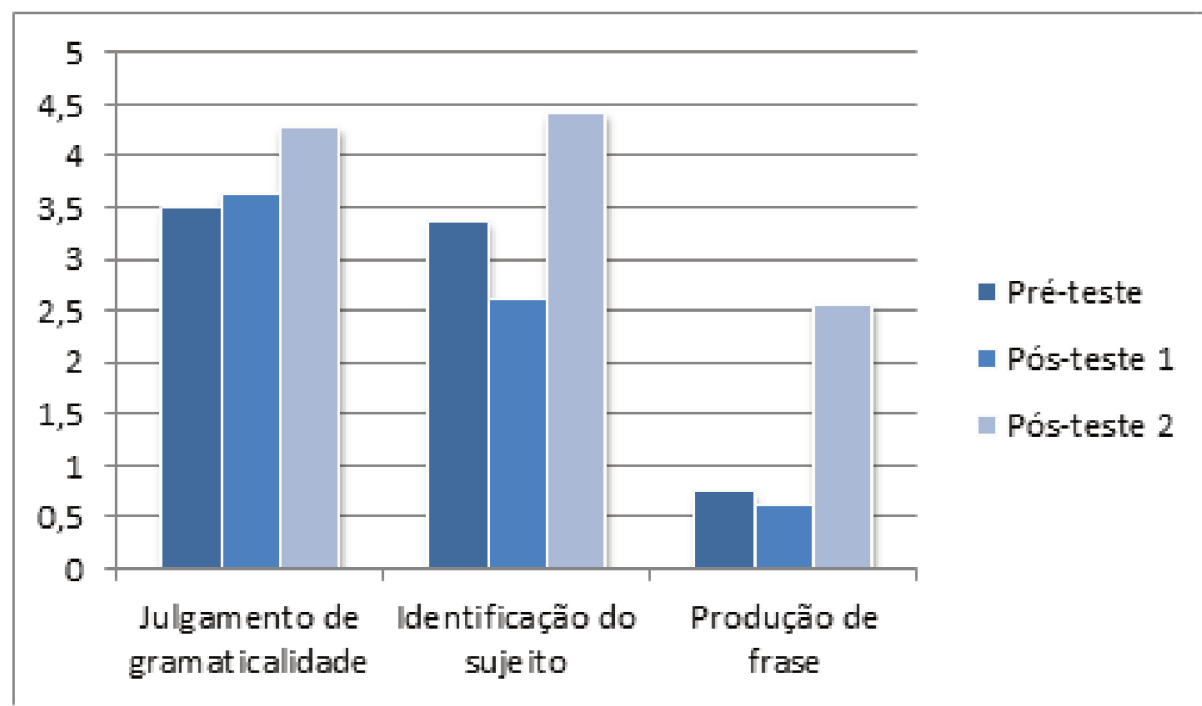

O segundo estudo, ainda não publicado (ORTIZ-PREUSS; OLIVEIRA JÚNIOR; ALMEIDA; RODRIGUES, em preparação), trata de um experimento que objetivava observar diferenças de efeitos de feedback explícito e implícito na 
aprendizagem de tempos verbais no pretérito em espanhol, correlacionando os resultados com testes de memória de trabalho e atenção. O foco no feedback se justifica porque os três tempos verbais alvo já haviam sido estudados separadamente pelos participantes, mas ainda não havia sido feita uma abordagem integrada com os três tempos.O experimento foi realizado com uma amostra de conveniência composta por 15 aprendizes brasileiros, que estudavam no terceiro semestre de espanhol, divididos em dois grupos. O grupo que recebeu feedback explícito ${ }^{9}$ contava com 7 participantes (27,8 anos de idade média) e o grupo que recebeu feedback implícito contava com 8 participantes (23,6 anos de idade média). Os participantes preencheram o QELP e realizaram os testes de atenção, de memória de trabalho (reading span e alpha span),bem como os testes linguísticos, intercalados pelo período de instrução.No período instrucional o grupo de feedback implícito só recebia avaliações do tipo certo ou errado e o grupo de feedback explícito recebiacorreção acompanhada da regra de uso linguístico referente a cada caso. Os resultados mostraram que houve associação positiva entre a capacidade de memória de trabalho (CMT) e a acurácia na tarefa de completar frases com verbos no pretérito, no grupo de feedback explícito, indicando que quanto maior a CMT, maior a acurácia na tarefa de completar frases. Já no grupo de feedback implícito houve correlação entre CMT e a acurácia das respostas natarefa de julgamento de gramaticalidade (TJG), indicando que quanto maior a CMT, maior a acurácia no julgamento de gramaticalidade. Embora não tenha havido correlação entre as tarefas linguísticas e o teste de atenção (ANT), os dados envolvendo diferentes tarefas linguísticas mostraram que efeitos dos dois tipos de feedbackestão relacionados com a CMT dos participantes, sendo, portanto, este sistema cognitivo uma variável importante no desenvolvimento linguístico desses participantes. O Quadro 1 resume os dois estudos sobre efeitos de instrução.

Quadro 1: Síntese dos estudos sobre efeitos de instrução

\begin{tabular}{|l|l|}
\hline Autores & ORTIZ-PREUSS (2017) \\
\hline Instrução & Instrução de processamento sobre o verbo gostar em espanhol no Moodle \\
\hline DIs & atenção; conhecimento prévio (similaridade entre as línguas) \\
\hline Instrumentos & $\begin{array}{l}\text { QELP } \\
\text { Teste ANT } \\
\text { Pré- e pós-testes linguísticos (compreensão e produção de frases e julgamento } \\
\text { de gramaticalidade) }\end{array}$ \\
\hline Foco & Similaridade linguística \\
\hline Participantes & $\begin{array}{l}\text { 19 aprendizes brasileiros de espanhol, de nível inicial } \\
\text { GE: 8 participantes (5 F e 3 M); média de idade de 24 anos } \\
\text { GC: 11 participantes (6 F e 5 M); média de idade de 27,5 anos. }\end{array}$ \\
\hline Resultados & $\begin{array}{l}\text { Evidências de vantagem da combinação entre instrução de processamento e } \\
\text { instrução explícita, principalmente na produção com a estrutura-alvo. }\end{array}$ \\
\hline Autores & $\begin{array}{l}\text { ORTIZ-PREUSS; OLIVEIRA JÚNIOR; ALMEIDA; RODRIGUES (em prepa- } \\
\text { ração) }\end{array}$ \\
\hline
\end{tabular}




\begin{tabular}{|l|l|}
\hline Instrução & $\begin{array}{l}\text { Instrução implícita e explícita sobre verbos no pretérito do indicativo em } \\
\text { espanhol }\end{array}$ \\
\hline DIs & memória de trabalho e atenção \\
\hline Instrumentos & $\begin{array}{l}\text { QELP } \\
\text { Teste ANT } \\
\text { Teste de memória de trabalho } \\
\text { Pré- e pós-testes linguísticos (compreensão e produção de frases e julgamento } \\
\text { de gramaticalidade) }\end{array}$ \\
\hline Foco & Feedback (implícito e explícito) \\
\hline Participantes & $\begin{array}{l}\text { 15 aprendizes que frequentavam o terceiro nível do curso de espanhol/L2. } \\
\text { FE: 7 participantes, (5 F e 2 M); média de idade era de 27,86 anos. } \\
\text { FI: 8 participantes, (4 F e 4 M); média de idade era de 23,63 anos. }\end{array}$ \\
\hline Resultados & $\begin{array}{l}\text { - Houve correlação entre CF e CMT no grupo de feedback explícito: quanto } \\
\text { maior a CMT, maior a acurácia na tarefa de completar frases com verbos no } \\
\text { pretérito. } \\
\text { - Houve correlação entre TJG e CMT, no grupo de feedback implícito: quanto } \\
\text { maior a CMT, maior a acurácia na tarefa de julgamento de gramaticalidade } \\
\text { em frases com verbos no pretérito. }\end{array}$ \\
\hline
\end{tabular}

Por outro lado, os estudos sobre produção de fala observavam o desempenho da atenção, controle inibitório e efeitos da similaridade linguística. Nesse caso, os participantes, estudantes de um Centro de idiomas, realizavam uma tarefa de nomeação de desenhos, dentro do paradigma desenho-palavra e um teste de atenção (ANT). Além disso, os participantes também respondiam ao Questionário de Experiência Linguística e Proficiência - QELP - (MARIAN; BLUMENFELD; KAUSHANSKAYA, 2007; SCHOLL; FONTES, 2015) para evidenciar o seu perfil.

O primeiro estudo (ORTIZ-PREUSS; RODRIGUES, 2017) trata de um experimento em que se solicitava que os participantes nomeassem desenhos em sua L1 (português) ou L2 (inglês ou espanhol), conforme a pista da língua de nomeação, dada pelo formato e cor da moldura ( $\mathrm{L} 1$ = azul; L2 = vermelho). O estudo nos permitia avaliar o efeito da similaridade linguística e os custos de troca na realização da tarefa. $\mathrm{O}$ experimento foi realizado com uma amostra de conveniência composta por 17 bilíngues, ${ }^{10}$ sendo 7 bilíngues português-inglês (21 anos de idade média) e 10 bilíngues português-espanhol (30,7 anos de idade média). Todos os participantes estavam frequentando o sexto semestre de estudo de sua L2. Os participantes preencheram o QELP e realizaram a tarefa de nomeação e o teste de atenção (ANT). Os resultados mostraram que os tempos de reação (TR) dos bilíngues português-espanhol foram maiores do que os TR dos bilíngues português-inglês, isso indica que a similaridade linguística parece dificultar a nomeação dos desenhos para os bilíngues português-espanhol.Além disso, os resultados de ambos os grupos evidenciaram custo de troca assimétrico, ou seja, voltar para a L1 era mais demorado do que voltar para a L2, isso se justifica, pois a L1 era a língua mais forte e, por isso, requeria maior força de inibição. Diante desses dados, optou-se por replicar o estudo, com o objetivo de aumentar a amostra.

O segundo estudo (RODRIGUES, 2018) replicava o experimento descrito anteriormente em uma amostra de conveniência um pouco maior, para ver se os 
resultados corroborariam o estudo inicial. Esse segundo experimento foi realizado com uma amostra composta por 26 bilíngues, sendo 14 bilíngues português-inglês (27,2 anos de idade média) e 12 bilíngues português-espanhol (28,5 anos de idade média). Novamente todos os participantes frequentavam o sexto semestre de estudo de sua L2. Os resultados mostraram que não houve diferença significativa no desempenho dos dois grupos de bilíngues e que os resultados de ambos os grupos evidenciaram custo de troca assimétrico, ou seja, voltar para a L1 era mais demorado do que voltar para a L2. Esse resultado corrobora a ocorrência de custo de troca assimétrico, mas não indica efeito de similaridade entre as línguas.

Diante disso, buscou-se verificar qual seria o motivo para essa diferença nos resultados dos estudos. Uma análise mais detalhada do perfil dos participantes mostrou que havia uma grande diferença de idade entre os grupos de bilíngues do primeiro estudo (quase 10 anos), sendo que o grupo de bilíngues português-inglês era o mais jovem e foi o mais rápido nas nomeações. Mas no segundo estudo a diferença na média de idade dos grupos foi menor (menos de 2 anos) e não houve diferença significativa nos TR. Além disso, constatou-se que para a maioria dos bilíngues português-espanhol do segundo estudo, o espanhol não era a segunda língua em ordem de aquisição, mas sim a terceira. Essa diferença no perfil dos participantes pode ter motivado os resultados obtidos nas tarefas, uma vez que o exercício constante de troca de sistemas linguísticos pode estar mais aprimorado neste grupo, por lidar com pelo menos 3 línguas. Em outras palavras, nesses bilíngues português-espanhol há mais sistemas sendo ativados e suprimidos, logo, a prática constante de troca de línguas pode ter contribuído para que o grupo conseguisse resolver melhor o conflito gerado pela ativação de palavras em línguas muito parecidas, e pode ter minimizado o efeito de similaridade linguística.

Os resultados dos dois estudos corroboram o papel do controle inibitório na produção de fala, haja vista a ocorrência de custo de troca assimétrico. Por outro lado, como no segundo estudo não foi corroborado o efeito da similaridade linguística, fica evidente a necessidade de mais pesquisas com uma amostra maior e com média de idade e histórico linguístico mais homogêneo. O Quadro 2 resume os estudos sobre produção de fala.

Quadro 2: Síntese dos estudos sobre produção de fala

\begin{tabular}{|l|l|}
\hline Autores & ORTIZ-PREUSS; RODRIGUES (2017) \\
\hline DIs & Controle inibitório, atenção \\
\hline Instrumentos & $\begin{array}{l}\text { Tarefa de nomeação de desenhos envolvendo troca de línguas } \\
\text { QELP } \\
\text { Teste ANT }\end{array}$ \\
\hline Foco & Similaridade linguística \\
\hline Participantes & $\begin{array}{l}17 \text { bilíngues (6 } 6^{\circ} \text { nível de curso) } \\
\text { Inglês: } 7 \text { (2 F e } 5 \mathrm{M}) ; 21,14 \text { anos } \\
\text { Espanhol: } 10 \text { (7 F e 3 M); 30,7 anos. }\end{array}$ \\
\hline Resultados & $\begin{array}{l}\text { Similaridade linguística impõe mais dificuldade ao sistema retardando a } \\
\text { nomeação. } \\
\text { Voltar para a L1 é mais demorado. Indício de custo de troca assimétrico. }\end{array}$ \\
\hline
\end{tabular}




\begin{tabular}{|l|l|}
\hline Autores & RODRIGUES (2018) \\
\hline DIs & Controle inibitório, atenção \\
\hline Instrumentos & $\begin{array}{l}\text { Tarefa de nomeação de desenhos envolvendo troca de línguas } \\
\text { QELP } \\
\text { Teste ANT }\end{array}$ \\
\hline Foco & Similaridade linguística \\
\hline Participantes & $\begin{array}{l}\text { 26 bilíngues (6o nível de curso) } \\
\text { Inglês: } 14(10 \mathrm{~F} \text { e } 4 \mathrm{M}) ; 27,29 \text { anos } \\
\text { Espanhol: } 12 \text { (9 F e 3 M); 28,5 anos. }\end{array}$ \\
\hline Resultados & $\begin{array}{l}\text { - A nomeação é mais lenta nos contextos de troca em ambos os grupos. } \\
\text { - Voltar para a L1 é mais demorado. Indício de custo de troca assimétrico. } \\
\text { - A maioria dos participantes do grupo de espanhol tinha esse idioma como } \\
\text { sua 3a língua, ou seja, o exercício de troca de língua pode estar mais aprimo- } \\
\text { rado. }\end{array}$ \\
\hline
\end{tabular}

\section{Considerações finais}

O objetivo deste artigo é apresentar um breve panorama de estudos que evidenciam como o desempenho linguístico bilíngue é afetado,dediferentes formas, especialmentepor suas características individuais (ORTIZ-PREUSS; SANZ, 2016; SANZ; SERAFINI, 2018). Inicialmente, fez-se uma breve discussão teórica sobre aquisição de L2, enfocando variáveis contextuais (condições pedagógicas) e variáveis individuais (diferenças individuais) e argumentando que o produto da aquisição de L2 é o resultado da interação de ambas as variáveis e que é necessário compreender melhor como elas se inter-relacionam. Para isso, são necessários mais experimentos que enfoquem condições pedagógicas e variáveis individuais na aquisição de L2, pois isso irá ampliar nossa compreensão sobre todo o processo de aquisição de línguas.

Sob essa perspectiva os estudos relatados neste artigo foram realizados, à luz da psicolinguística do bilinguismo, em contextos formais de aquisição da L2. Os resultados obtidos ratificam o argumento de que as DIs e as condições pedagógicas interagem de diversas formas no processo de aquisição de L2, tendo feito, portanto, contribuição importante para a área de educação linguística. Ressaltese que os resultados são bastante incipientes, principalmente, devido ao tamanho reduzido das amostras. Finalmente, é necessário enfatizar alguns desafios da pesquisa nesta área. O primeiro se refere ao planejamento dos experimentos de modo a garantir o rigor metodológico de pesquisas experimentais em estudos realizados em contextos formais de aquisição de L2. O segundo se refere à importância de se incluir os conhecimentos produzidos na área da psicolinguística do bilinguismo nos currículos dos cursos de formação de professores, para que esses profissionais, além de receber e reproduzir receitas de ensino, estejam aptos a fazer diagnósticos adequados de seus aprendizes e elencar as formas de intervenção pedagógica mais compatíveis com as DIs de cada grupo. 
Notas

1. Este texto é oriundo da comunicação oral apresentada no ENCONTRO DO GT DE PSICOLINGUÍSTICA, no XXXIII Encontro Nacional da ANPOLL - ENANPOLL, em junho de 2018, na Universidade Federal de Mato Grosso UFMT, em Cuiabá.

2. Neste artigo usamos como sinônimos os termos diferenças individuais e variáveis individuais ou internas, para referir-nos às características pessoais dos aprendizes (ORTIZ-PREUSS; SANZ, 2016).

3. Neste artigo vamos enfocar algumas características individuais, as quais serão descritas com mais detalhe na próxima seção, entretanto, esclarecemos que: 1) conhecimento linguístico prévio significa a(s) língua(s) que o indivíduo sabe ao aprender uma nova língua, por exemplo a L1 em relação à L2; 2) inibição, neste caso, refere-se ao mecanismo de controle que suprime a ativação de um sistema linguístico não-alvo; 3 ) memória de trabalho é um sistema operacional que retém e processa informação durante a realização de uma tarefa; e 4) atenção é um sistema cognitivo que controla o acesso à consciência.

4. Variáveis contextuais se referem aos aspectos do contexto em que ocorre o processo de aquisição da L2 (ORTIZ-PREUSS; SANZ, 2016).

5. Os termos aquisição e aprendizagem serão usados intercambiavelmente neste artigo.

6. Devido ao escopo do artigo, não faremos a descrição detalhada de cada intervenção. Ao leitor interessado recomendamos a leitura de ELLIS (1998; 2005).

7. Nesta intervenção, os dados do input são manipulados e a atenção do aprendiz é direcionada durante o processamento de informações, de modo a contemplar os princípios de processamento, baseados nas tendências naturais de processamento de sentenças (VANPATTEN, 2005).

8. Neste artigo apresentaremos um breve resumo dos experimentos, enfatizando os seus principais resultados, haja vista que os resultados já foram ou serão publicados em outros artigos devidamente referenciados.

9. A definição do tipo de feedback para cada grupo foi feita de forma aleatória.

10. Ressalte-se que são bilíngues ainda em fase de aquisição de sua L2.

\section{Referências}

BADDELEY, A. Memória de trabalho. In: BADDELEY, A.; ANDERSON, M. C.; EYSENCK, M. W. Memória. Porto Alegre: Artmed, 2011, p. 54-81.

BADDELEY, A. D.; ANDERSON, M. C.; EYSENCK, M. W. Memória. Porto Alegre: Artmed, 2011.

BADDELEY, A. D.; ANDERSON, M. C.; EYSENCK, M. W. Is working memory still working? European Psychologist. v. 7, n. 2, p. 85-97, June. 2002.

BOWDEN, H. W.; SANZ, C.; STAFFORD, C. A. Individual differences: Age, sex, working memory, and prior knowledge. In: SANZ, C. (ed.). Mind and Context in adult second language acquisition: methods, theory, and practice. Washington DC: GUP, 2005, p. 105-140.

COSTA, A.; HERNÁNDEZ, M.; SEBASTIÁN-GALLÉS, N. Bilingualism aids conflict resolution: evidence from the ANT task. Cognition. V. 106. Elsevier Science B.V. 2008. p. 59-86.

COSTA, A.; SANTESTEBAN, M.; IVANOVA, I. How do highly proficient bilinguals control their lexicalization process? Inhibitory and language-specific selection 
mechanisms are both functional. Journal of Experimental Psychology: learning, memory and cognition, v. 32, (5). Washington, DC: American Psychological Association, 2006, p. 1057-1074.

DOUGHTY, C.; WILLIAMS, J. (eds.).Atención a la forma en la adquisición de segundas lenguas en el aula. Madrid: Editorial Edinumen, 2009.

ELLIS, R. La adquisición de segundas lenguas en un contexto de enseñanza: análisis de las investigaciones existentes. Auckland: Ministry of Education, New Zealand, 2005. Disponível em:<http://www.mecd.gob.es/dctm/redele/Material-RedEle/ Biblioteca/2006_BV_05/2006_BV_05_04Ellis.pdf?documentId=0901e72b80e 3a029> . Acesso: março de 2019.

ELLIS, R. Teaching and Research: Options in Grammar Teaching. TESOL Quarterly, v. 32, n. 1, p. 39-60, 1998.

FINGER, I.; ORTIZ-PREUSS, E. A Psicolinguística do bilinguismo: estudando o processamento linguístico e cognitivo bilíngue. In: ORTIZ-PREUSS, E. FINGER, I. (org,). A dinâmica do processamento bilingue. Campinas/SP: Pontes Editores, 2018, p. 31-57.

FINGER, I.; ORTIZ-PREUSS, E. Atenção ao input e aprendizagem: o papel da instrução explícita na aquisição do espanhol como L2. Letras de Hoje, Porto Alegre, v. 44, n. 3, p. 78-85, 2009.

GASS, S.; SELINKER, L. Second language acquisition: An introductory course. $3^{\mathrm{a}} \mathrm{ed}$. New York: Routledge: 2008.

GROSJEAN, F.; LI, P. The psycolinguistics of bilingualism. Oxford: Wiley-Blackwell, 2013.

IZUMI, S. Noticing and L2 Development: Theoretical,Empirical, and Pedagogical Issues. In:BERGSLEITHNER,J. M.; FROTA, S. N.; YOSHIOKA, J. K. (Ed.).Noticing and Second Language Acquisition: Studies in Honorof Richard Schmidt. Honolulu: National Foreing LanguageResource Center, 2013. p. 25-38.

JUFFS, A.; HARRINGTON, M. Aspects of working memory in L2 learning. Language Teaching. No 44 (2), CUP, 2011, p. 137-166.

JUST, A. M; CARPENTER, P. A. A Capacity Theory of Comprehension: Individual Differences in Working Memory. Psychological Review, v. 99, n. 1, 1992, p. 122149.

KRAMER, R. Effects of bilingualism on inhibitory control and working memory: a study with early and late bilinguals. Dissertação de mestrado. Programa de pósgraduação em Letras/Inglês e Literatura correspondente. Florianópolis: UFSC, 2011. $201 \mathrm{p}$.

LEITÃO, M. M. Psicolinguística Experimental: focalizando o processamento da linguagem. In: MARTELOTTA, M.E. (org.). Manual de Linguística. 1a Ed., $1^{\text {a }}$ reimpressão. São Paulo: Contexto, 2008. P. 217-234.

LONG, M. H.; ROBINSON, P. La atención a la forma: teoría, investigación y práctica. In: DOUGHTY, C.; WILLIAMS, J. (eds.). Atención a la forma en la adquisición de segundas lenguas en el aula. Madrid: Editorial Edinumen, 2009. p. 29-56.

MARIAN, V.; BLUMENFELD, H. K.; KAUSHANSKAYA, M. The Language Experience And Proficiency Questionnaire (LEAP-Q): Assessing language profiles in bilinguals and multilinguals. Journal of Speech, Language, and Hearing Research, 50(4), 2007.

ORTEGA, L. Cognition. In: ORTEGA, L. Understanding second language acquisition. New York, Routledge, 2013, p. 82-109. 
ORTIZ-PREUSS, E. Ensino do verbo gustar em espanhol para brasileiros: intervenção pedagógica baseada na instrução de processamento. Revista Letrônica, Porto Alegre, v. 10, n. 2, 2017, p. 789-804.

ORTIZ-PREUSS, E; RODRIGUES, T. B. Produção de fala bilíngue: avaliando similaridade linguística, custos de troca entre línguas e sistema atencional. Revista Ilha do Desterro.Florianópolis, v. 70, nº 3, 2017,p. 63-79.

ORTIZ-PREUSS, E; SANZ, C. Aquisição de L2: Interação entre variáveis externas e internas. In: ORTIZ-PREUSS, E.; COUTO, E. K. N. N. do; RAMOS, R. M. do. (orgs.). Múltiplos olhares e Linguística e Linguística Aplicada. Campinas: Pontes, 2016, p.121-134.

ORTIZ-PREUSS, E. Similaridade linguística entre português e espanhol: efeitos na produção de fala em L2.Revista (Con) Textos linguísticos. Vitória: PPGEL-UFES, v. 8, n. 10, p. $66-82,2014$.

ORTIZ-PREUSS, E; FINGER, I. O papel da instrução na aquisição do Espanhol como L2: um estudo sobre o seoperador aspectual como delimitador. Linguagem \& Ensino, Pelotas, v.12, n.2, p.435-462, 2009.

ORTIZ-PREUSS, E; OLIVEIRA JÚNIOR, W. J. de; ALMEIDA J. B.; RODRIGUES, R. R.Diferenças individuais e efeitos de feedback na aquisição de verbos no pretérito em espanhol como L2. (em preparação).

REZNITSKAYA, A. Introdução à pesquisa como investigação quantitativa. In: LANKSHEAR, C.; KNOBEL, M. Pesquisa Pedagógica: do projeto à implementação. Porto Alegre: Artmed, 2008. p. 126-145.

RODRIGUES, T. B.Acesso lexical e produção de fala em L2: efeitos de similaridade linguística e atenção. 2018. 106 f. Dissertação (Mestrado) Curso de Letras Linguística, Universidade Federal de Goiás, Goiânia, 2018. Disponível em: <http://repositorio.bc.ufg.br/tede/bitstream/tede/8937/5/ Disserta\%C3\%A7\%C3\%A3o\%20-\%20Taiany\%20Braz\%20Rodrigues\%20-\%20 2018.pdf > Acesso em: 03 jan. 2019.

SANZ, C. Adult SLA: The interaction between external and internal factors. In: SANZ, C. (ed.). Mind and Context in adult second language acquisition: methods, theory, and practice. Washington DC: GUP, 2005, p. 3-20.

RODRIGUES, T; SERAFINI, E. J. Cognición y L2: El papel de las diferencias individuales en el aprendizajede lenguas extranjeras con especial atención a la memoria operativa. In: ORTIZ-PREUSS, E. FINGER, I. (org,). A dinâmica do processamento bilingue. Campinas/SP: Pontes Editores, 2018, p. 233-267.

RIGATTI, P. C. Um estudo sobre a correlação entre memória de trabalho e compreensão leitora com falantes de português brasileiro. TCC. Curso de Letras da Universidade Federal do Rio Grande do Sul. 2015, 70 p.

SCHOLL, A. P.; FONTES, A. B. A. da L. (tradução). Questionário de Experiência Linguística e Proficiência - QELP, 2015.

SCHMIDT, R. Attention, awareness, and individual differences in language learning. In: CHAN, W. M.; CHI, S.; CIN, K. N.; ISTANTO, J.; NAGAMI, M.; SEW, J. W.; SUTHIWAN, T.; WALKER, I. Proceedings of CLaSIC 2010. Singapura: National University of Singapore, Centre for Language Studies, 2010. p. 721-737.

SUTHIWAN, T.; WALKER. Attention. In: ROBINSON, P. (Ed.). Cognition and second language instruction. Cambridge: Cambridge University Press, 2001, p. 3-32.

SUTHIWAN, T.; WALKER. Consciousness and Foreign Language Learning: a tutorial on the role of attention and awareness in learning. In: SCHMIDT, R. 
(Ed.). Attention and awareness in foreign language learning. Honolulu, Hawaii: University of Hawaii, 1995. p. 1-63.

SUTHIWAN, T.; WALKER. Deconstructing consciousness in search of useful definitions for Applied Linguistics. In: Consciousness in Second Language Learning. AILA Review, n.11, p. 11-23, 1994.

SUTHIWAN, T.; WALKER. The role of consciousness in second language learning. Applied Linguistics, v.11, p.129-158, 1990.

VANPATTEN, B. Processing instruction. In: SANZ, C. (ed.). Mind and Context in adult second language acquisition: methods, theory, and practice. Washington DC: GUP, 2005, p. 267-281.

VANPATTEN, B. Processing Instruction: An Update. Language Learning, v. 52, n.4, 2002, p. 755-803.

VANPATTEN, B. Input Processing and Grammar Instruction in Second Language Acquisition. Ablex Publishing Corporation: New Jersey, 1996.

YE, Z. ZHOU, X. Executive control in language processing. Neuroscience and biobehavioral reviews. № 33. 2009, p. 1168-1177.

Recebido em: 09/03/2019

Aceito em: 30/07/2019 